\title{
Application areas of augmented reality and virtual reality in construction project management: A scoping review
}

\author{
Mahmoud Albahbah ${ }^{1}$ iD, Serkan Krvrak*1 ${ }^{* 1}$, Gökhan Arslan² ${ }^{\text {iD }}$ \\ ${ }^{1}$ Eskişehir Technical University, Department of Civil Engineering, Eskişehir, Turkey \\ ${ }^{2}$ Yalova University, Department of Civil Engineering, Yalova, Turkey
}

\begin{abstract}
Augmented reality (AR) and virtual reality (VR) are advanced technologies that can provide significant advantages to the construction industry. In recent years, many researchers have focused on implementing AR and VR technologies in the construction project management domain, where these technologies have shown a significant contribution to the advancement of the construction project management aspects in many areas. However, there is a lack of a structured review that synthesizes the existing body of knowledge about the implementation of AR and VR technologies in the various aspects of construction project management. Therefore, this study aims to fill this gap via conducting a scoping review on the application areas of AR and VR technologies in construction project management. Ninety-four studies retrieved from peer-review journals and conference proceedings were included, reviewed, and analyzed. The studies were classified according to publication date, publication venue, study design, and geographical location. The main features of AR and VR systems, including the display method, interaction device, spatial registration method, and level of immersion, were identified and discussed. The application areas of each technology were thematically analyzed and classified under main topics, where the results revealed seven application areas for AR technology and five application areas for VR in the construction project management aspects.
\end{abstract}

\section{Keywords}

Augmented reality; Virtual reality; Construction project management; Construction industry; Scoping review

Received: 07 September 2021; Accepted: 28 September 2021

ISSN: 2630-5771 (online) (C) 2021 Golden Light Publishing All rights reserved.

\section{Introduction}

AR and VR technologies are implemented in many industries and practical programs such as education, design, manufacturing, entertainment, and healthcare. Despite that the construction industry is one of the least digitized industries, it is increasingly moving towards embracing more and more computer-based technologies to provide better performance in various stages of construction projects, and visualization is one of the main application areas [1]. AR and VR technologies are advanced technologies that can provide significant advantages through visualization to the construction industry. The increased need of the construction industry for visualization technologies such as AR and VR arises from the complex nature of the industry and its high demand for information access for assessment, communication and collaboration [2-4].

\footnotetext{
* Corresponding author

Email: serkankivrak@eskisehir.edu.tr
} 
Many researchers have drawn attention to the benefits and implementations of $\mathrm{AR}$ and VR technologies in the architecture, engineering, and construction (AEC) industry [3,5]. Although the effective use of AR and VR in the construction industry is not easy, various areas in the construction sector have shown a successful implementation of these technologies as desired [6]. Researchers have paid attention to synthesize the research activities about the applications of AR and VR technologies in the construction industry [711]. Many researchers have focused on the implementation of $\mathrm{AR}$ and $\mathrm{VR}$ technologies in construction project management (CPM) where these technologies have shown a significant contribution to the advancement of this sector in many areas such as cost and time management, defect management, safety management, education and training, progress monitoring and tracking, and information collection. However, there is a lack of a structured review that synthesizes the existing body of knowledge about the implementation of AR and VR technologies in the various aspects of CPM. Therefore, this study aims to fill this gap by introducing a structured, comprehensive scoping review to reflect these technologies' present status in the CPM domain, which would provide a solid platform for the researchers and construction practitioners to explore the potential application areas, understand the effective use of these technologies, and explore new use cases.

\section{2. $A R$ and $V R$ in construction industry}

AR impacts the mobile computing industry by radically shifting the interaction between humans and computers [5], as AR creates direct, automatic, and practicable connections between the physical world and digital information by providing a simple and immediate user interface to a digitally enhanced physical world [12]. Furht [13] defined AR as a real-time view of a real-world environment that has been augmented by adding virtual digital information to it. On the other hand, VR refers to a computer simulation that generates a view that appears to the user's senses in much the same way that perceives the real world [14]. VR is composed of an interactive computer simulation that allows users to physically participate in a synthetic world through sensing the user's position and actions and change or augments sensory feedback information to one or more senses $[14,15]$. Fuchs et al. [16] proposed a technical definition of VR as it is a scientific and technical domain that uses behavioral interfaces and computer science to emulate the behavior of $3 \mathrm{D}$ entities in a virtual world, which interact with each other in real-time and with one or more users through sensorimotor channels in pseudo-natural immersion. Confusion exists between VR and AR, which is a long-running issue [17]. Both technologies have a similar approach and shares some underlying technologies, yet they display distinctly diverse experiences [18]. In simple words, VR differs from AR in a way that in $\mathrm{VR}$, the real elements are removed, and the user is immersed in a virtual environment with virtual objects [17], while AR provides the user additional visual information overlaid on the real world [18]. Several AR application areas in the construction industry such as building and inspection [19-21], scheduling and construction progress monitoring $[22,23]$, quality and defect management [24,25], communication and information retrieval $[8,26,27]$, and safety management and workers training $[28,29]$ have been investigated. The use of AR as a stand-alone solution or in combination with other supporting technologies provide several benefits for construction industry:

- The essential benefit of AR is that it enables the user to receive computer-mediated contextual information that is not otherwise easily accessible [30].

- Enables all project parties to collaborate effectively throughout the construction process [31].

- Improves the health and safety of the work environment, for instance, by reducing the usermachine interaction [32].

- Provides a significant cost and time saving through identifying clashes at the early stages of design and construction, especially in complex projects [33]. 
On the other hand, several VR application areas in the construction industry such as visualization and collaboration [34-37], safety management [10,38-41], and construction engineering education and training [11,42-44] have been investigated. As the AEC industry relies heavily on visual communication, the advances in VR technology offers considerable benefits to the industry [45]. Based on the study of Ozcan-Deniz [46], in medical buildings, the VR mockup cost was reported to be less than $15 \%$ of the proposed physical mockup. According to the study of Kim et al. [45], the application areas of VR in the built environment can be classified as architecture and design, construction, training and education, landscape and urban planning, engineering, facility management, and lifecycle integration. According to the study of Delgado et al. [7], the major driving factor of adopting VR and AR in the construction industry is that these technologies can improve the delivery of construction projects, also it can contribute to improve project understanding, productivity, communication and collaboration. The major limitation factor of adopting VR and $A R$ in the construction industry is the perception that these technologies are still immature that cannot be fully used in practice yet [7].

\section{Scoping reviews}

Scoping reviews have become an increasingly common approach for synthesizing the literature on a particular topic [47-49]. One of the most commonly cited definitions of scoping review is the one suggested by Arksey and O'Malley [49]: "scoping studies aim to map rapidly the key concepts underpinning a research area and the main sources and types of evidence available, and can be undertaken as stand-alone projects in their own right, especially where an area is complex or has not been reviewed comprehensively before". Arksey and O'Malley [49] identified four common reasons why a scoping review might be conducted:

- To examine the size, scope, and quality of research activity: in such an approach, describing research results in any detail might not be provided. However, this is a useful way to map study areas where it is difficult to visualize the range of available materials.

- To define the importance of conducting a full systematic review.

- To summarize and publicize research outcomes: in this type of scoping review, a description in more detail of research outcomes in a particular area of study might be provided.

- To identify research gaps in the existing literature.

Tricco et al. [50] found that out of 494 included scoping reviews, Arksey and O'Malley's framework was the most frequently cited guide for conducting the scoping review. The developed framework is considered not a linear but iterative process consisting of five stages and an optional sixth stage [49]. The first stage includes identifying the research question. Within this stage, considering the important aspects of the research question, such as study population, interventions, or outcomes, would help researchers shape the review parameters [49]. The second stage identifying relevant studies should be aligned with the whole point of this type of review, which is to be as comprehensive as possible. The research team has to make decisions related to the coverage and breadth of the review in terms of data sources, search methods, inclusion criteria, time span, and language to limit the scope of the review [49]. In the third stage that called study selection, inclusion and exclusion criteria are applied to identify relevant studies to be included and eliminate studies that do not address the research question [49]. Once the articles are identified, the fourth stage called "charting the data", involves charting and sorting the obtained information according to key items and issues $[48,49]$. The fifth stage includes collating, summarizing, and reporting results. The last and optional stage includes consulting with stakeholders to inform consulting with stakeholders to report or support study results $[47,49]$.

\section{Methodology}

The main objective of this study is to systematically map the development and trends of AR and VR in CPM through exploring the size, range, and nature 
of the existing literature about the AR and VR applications in the CPM and identifying the critical application areas of these technologies in the CPM domain. The scoping review method was chosen in this study due to the consistency of the study objectives with the method, the broad nature of the research questions [47-49,51], the diverse nature of the topic, and the flexibility in the selection and inclusion of literature, which is essential for literature assessment within the CPM field where there is no consistent paradigm regarding the study design [52]. The methodology of this study was guided by the proposed framework outlined by Arksey and O'Malley [49], in addition to some of the enhanced recommendations made by Levac et al. [47], Daudt et al. [48], and Colquhoun et al. [53]. The methodology followed up the five stages as mentioned in the previous section however, the optional component of the framework "consultation exercise" was not included.

\subsection{Identifying the research questions}

As a starting point for conducting a review, appropriate broad research questions with a clearly articulated scope of inquiry were identified and linked to the purpose at the outset of the review as proposed by Levac et al. [47] and Daudt et al. [48], which led to establishing an effective search strategy. The following formulated questions guided this study:

- What studies have been conducted on AR and VR in CPM?

- What is known from the existing literature about the applications of AR and VR in CPM?

- What are the key application areas of AR and VR in CPM?

- What are the types and characteristics of AR and VR technologies used in CPM?

\subsection{Identifying relevant studies}

After identifying the research questions and aims, methodical guidelines were set to guide the following stages (Table 1). Identifying relevant studies requires being as comprehensive as possible for covering the field to identify the existing literature suitable for answering the central research questions [47-49,51]. Therefore, the research strategy adopted different sources to identify relevant studies $[48,49]$ which are electronic databases, hand-searching of key journals, and relevant conference. Some limits related to the time span and the language were placed on the search strategy to balance comprehensiveness, breadth, and feasibility [47-49]. Initially, the search was started through two databases (Web of Science and ASCE library) that are supposed to compromise master journals and publishers regarding the scientific field of construction management in an unbiased manner [52]. The search targeted the published studies in peer-reviewed journals and conference proceedings published between 2008 and 2020. Only the studies that have been published in English were targeted due to the time and cost involved in the translation process. The keywords "augmented reality" and "virtual reality" was used. The initial search generated an unmanageable amount (over 35000) of hits, so to narrow the search towards the CPM field, a combination of technical topics and sub-headings such as construction management, project management, and construction were used to fit the databases of Web of Science and ASCE library, respectively. The reference lists from a set of relevant key papers (such as review articles) were scanned to identify other potential papers that may not be included in the databases. Afterwards, a hand-search was conducted for a set of key journals that have demonstrated a high number of relevant papers within the initial search in the databases. Also, the proceedings of the International Council for Research and Innovation in Building and Construction (CIB W78) conference were searched using the ITC Digital library as it is a relevant conference to the advanced technology in construction.

\subsection{Study selection}

A two-stage screening process was used to evaluate the relevance of the identified citations to the research questions. 
Table 1. Methodical guidelines used in the study

\begin{tabular}{|c|c|c|c|}
\hline General guidelines & Sources & Extracted data & Reporting the results \\
\hline $\begin{array}{l}\text { - Sources: electronic } \\
\text { databases, selected } \\
\text { journals, relevant } \\
\text { conference } \\
\text { - } \\
\text { - } \\
\text { - } \\
\text { - } \\
\text { - Simglish lang span: }(2008-2020) \\
\text { review must be peer- } \\
\text { conference } \\
\text { proceedings }\end{array}$ & $\begin{array}{l}\text { - } \text { Web of Science } \\
\text { - } \\
\text { - } \\
\text { ITC D Digital library } \\
\text { for proceedings of } \\
\text { CIB W78 } \\
\text { conference }\end{array}$ & $\begin{array}{l}\text { - Title, author(s), } \\
\text { publication year, } \\
\text { country/region, } \\
\text { - Journal/Conference } \\
\text { - } \quad \text { Reported study design } \\
\text { - } \quad \text { Type of technology } \\
\text { - } \quad \text { Technology features } \\
\text { - } \\
\text { - } \\
\text { - Key findings }\end{array}$ & $\begin{array}{l}\text { - } \\
\text { Descriptive } \\
\text { summaries } \\
\text { - } \quad \text { Statistical } \\
\text { summaries } \\
\text { - Visual illustrations } \\
\text { (charts and } \\
\text { graphs) and tables }\end{array}$ \\
\hline
\end{tabular}

In the first screening stage, a screening process of the title, abstract, and keywords for all the generated hits was conducted using a prepared relevance screening form (Appendix A1) to remove irrelevant studies. In case of existing ambiguity about the relevance of the study after screening the abstract, an investigation of the full-text article was conducted. Titles for which an abstract was not available were included for the subsequent stage of screening full text. In the second screening stage, a full-text eligibility screening was conducted for all the studies (that were deemed relevant in the first stage) using an eligibility screening form (Appendix A2) to make the final decision about including the studies in the review. The included studies must fit the following criteria: only studies that were published between 2008 and 2020, available in English, full-text available, and published in peer-reviewed journals or conference proceedings. The included studies must deal with the application of AR or VR in areas of the CPM, where those studies regarding solely to AR or VR rather than their applications in CPM were not included. The study was excluded if the full text was not available (e.g. conference abstracts). All the identified citations from the databases were imported into bibliographic citation management software Endnote X9 to manage bibliographies, organize and cross-check the data, and remove duplicates. Furthermore, the software was compatible with the used Microsoft Word package, which provided a quick and easy task to produce lists of references for inclusion in the study.

\subsection{Charting the data}

This stage involved extracting the important data and variables from the full-text records (that included in the review for the final analysis) to address the research questions [47]. A data charting form was developed based on numerous dimensions that would answer the research question. The data extraction process was iterative, and the data-charting form was continually updated as proposed by Levac et al. [47]. The final datacharting form contained the following data when available: general information regarding study (title, author(s), publication year, country/region, type of article/study, journal/conference); reported study design (quantitative, qualitative, mixed); type of technology (AR, VR); technology features; application area; and key findings. All the included studies in the final review were imported to NVivo 12 software to identify, code, and extract the units of text related to the key components of the data charting form.

\subsection{Collating, summarizing, and reporting the results}

In order to analyse the size, range, and nature of the existing studies, descriptive numerical summaries were used to describe the characteristics of the included studies. The description of these characteristics includes the process of identifying and selecting studies, classification of studies by date, journal, geographical distribution, and the reported study design. Later, the extracted units 
related to the application areas of $\mathrm{AR}$ and VR technologies in CPM, and the types and characteristics of these technologies were analysed and organized thematically under thematic categories [47-49], where the results are reported as a combination of narrative summaries and tables.

\section{Results and discussion}

\subsection{Search and selection of studies}

The research strategy initially identified 5207 potentially relevant articles through the search of the electronic databases, and 32 articles were identified as proceedings of the CIB W78 conference through the search in the ITC Digital library. Through removing duplicates and the first stage of screening title, abstract, and keywords, 5065 articles were excluded, while 174 articles were retrieved for the next stage of screening, addition to 20 articles was identified through the hand-search. The screening of the full-text records of the remaining articles excluded 100 studies for not meeting the eligibility criteria or being duplicated, while 94 articles were included in the final analysis. The flow of articles from the initial identification to the final inclusion is demonstrated in Fig. 1. The final included studies are classified as 42 studies related to AR, 46 studies related to VR, and 6 studies related to both AR and VR.

\subsection{Classification of studies by publication year}

Fig. 2 shows the number of studies by publication year. From 2008 to 2012, relevant studies were published in series of low numbers with an average of 2.8 publications per year. 2013 represents the first peak of the publication rate where there was a rapid and significant increase in the publication number (11), about four times more than the average number of publications in previous years.

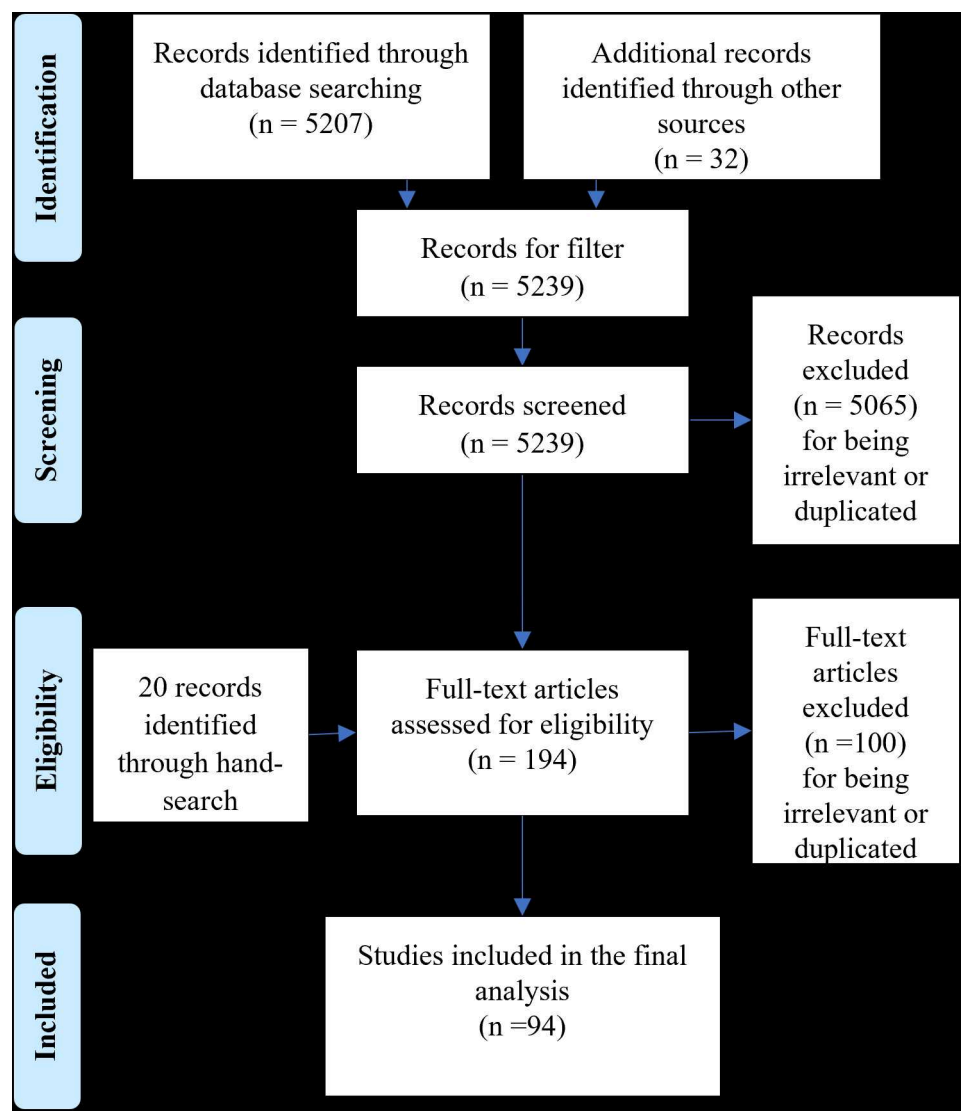

Fig. 1. Scoping review flowchart 


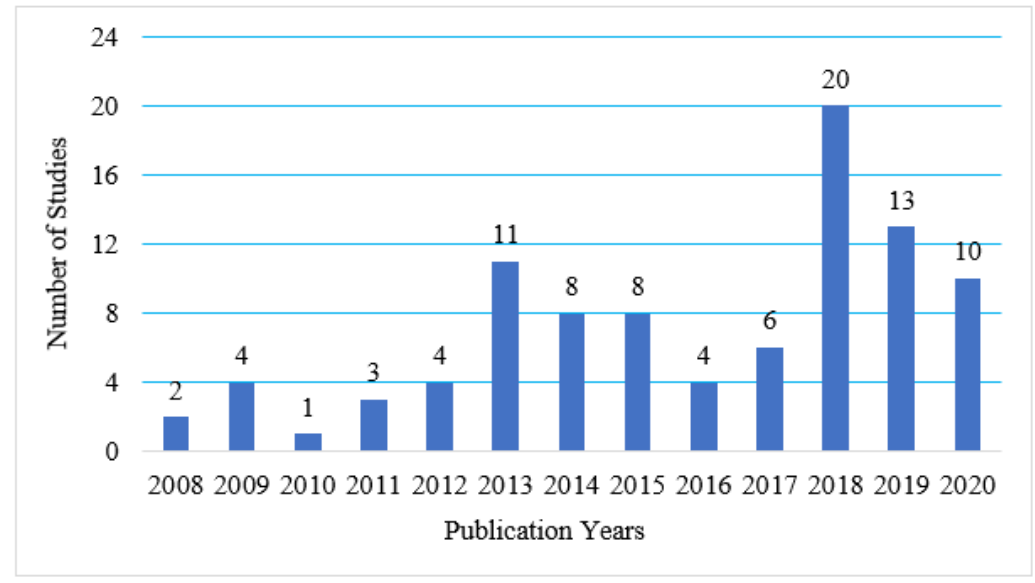

Fig. 2. Publications per year

The publication rate between 2013-2020 has an average number of 10 publications per year. 2018 represents the highest number of publications within the review time frame, with 20 publications per year, about four times more than the average (5.1) in previous years. Despite the drop in the publication number in 2019 and 2020 compared to 2018 , it is still more than the total average of the publication rate. This substantial increase in the publication rate may indicate that the interests and efforts in AR and VR research in the CPM domain have increased, and this trend will continue.

\subsection{Classification of studies by publication venue and study design}

The included studies are classified according to the publication venue and the reported study design in this section. Of the 94 included studies, 70 (74\%) studies were identified as a journal paper and 24 (26\%) studies as a conference proceeding. Table 2 presents the distribution of identified studies categorized based on publication venue. The results demonstrate that $50 \%$ of the identified studies are published in the following sources: Automation in Construction, Journal of Computing in Civil Engineering, and American Society of Civil Engineering (ASCE) Conferences, where the Automation in Construction journal contributes with the highest publication rate $(21 \%)$ to the research topic with 20 studies. Furthermore, the publication distribution reveals multidisciplinary research efforts of AR and VR in the CPM aspects, where the identified studies were mainly published in technology-related journals and conferences and within the area of construction engineering and management. This observation represents a valuable clue for the academics and researchers interested in the AR and VR applications in the CPM where it provides an important indicator of where to find relevant research and where to submit research.

The studies were also categorized according to the reported study design as either "Quantitative", "Qualitative", or "Mixed Method". The quantitative method represents the dominant approach with the highest proportion (66\%) as a used methodology within the classified studies, followed by the mixed-method methodology (25\%), and the qualitative methodology appears with the lowest proportion (9\%). It should be mentioned that three studies were not classified due to the lack of sufficient information about the used methodology.

\subsection{Classification of studies by country}

The identified studies were classified based on the geographical location of the corresponding authors' institution or university. Fig. 3 illustrates the sorting of publications according to the geographical location. The geographical distribution of the publications represents almost $10 \%$ of all countries recognized by the UN. 
Table 2. Distribution of the identified studies by publication venue

\begin{tabular}{|c|c|c|}
\hline Journal List & Number of Studies & Percentage \\
\hline Automation in Construction & 20 & $21 \%$ \\
\hline Journal of Computing in Civil Engineering & 12 & $13 \%$ \\
\hline Journal of Construction Engineering and Management & 4 & $4 \%$ \\
\hline Visualization in Engineering & 4 & $4 \%$ \\
\hline Safety Science & 3 & $3 \%$ \\
\hline Journal of Information Technology in Construction & 3 & $3 \%$ \\
\hline KSCE Journal of Civil Engineering & 3 & $3 \%$ \\
\hline International Journal of Engineering Education & 3 & $3 \%$ \\
\hline Construction Innovation & 2 & $2 \%$ \\
\hline Construction Management Economics & 2 & $2 \%$ \\
\hline Journal of Civil Engineering and Management & 2 & $2 \%$ \\
\hline Engineering, Construction and Architectural Management & 2 & $2 \%$ \\
\hline Advances in Civil Engineering & 1 & $1 \%$ \\
\hline Building a Sustainable Future & 1 & $1 \%$ \\
\hline Buildings & 1 & $1 \%$ \\
\hline Journal of Architectural Engineering & 1 & $1 \%$ \\
\hline Journal of Intelligent \& Robotic Systems & 1 & $1 \%$ \\
\hline Journal of Management in Engineering & 1 & $1 \%$ \\
\hline $\begin{array}{l}\text { Journal of Professional Issues in Engineering Education and } \\
\text { Practice }\end{array}$ & 1 & $1 \%$ \\
\hline Teknik Dergi & 1 & $1 \%$ \\
\hline Organization Technology and Management in Construction & 1 & $1 \%$ \\
\hline International Journal of Environmental Research Public Health & 1 & $1 \%$ \\
\hline \multicolumn{3}{|l|}{ Conference List } \\
\hline American Society of Civil Engineering (ASCE) Conferences & 16 & $17 \%$ \\
\hline $\begin{array}{l}\text { International Council for Research and Innovation in Building } \\
\text { and Construction (CIB W78) }\end{array}$ & 5 & $5 \%$ \\
\hline International Conference Structures and Architecture (ICSA) & 1 & $1 \%$ \\
\hline Winter Simulation Conference (WSC) & 1 & $1 \%$ \\
\hline International Symposium on System Integration (SII) & 1 & $1 \%$ \\
\hline Total & 94 & $100 \%$ \\
\hline
\end{tabular}




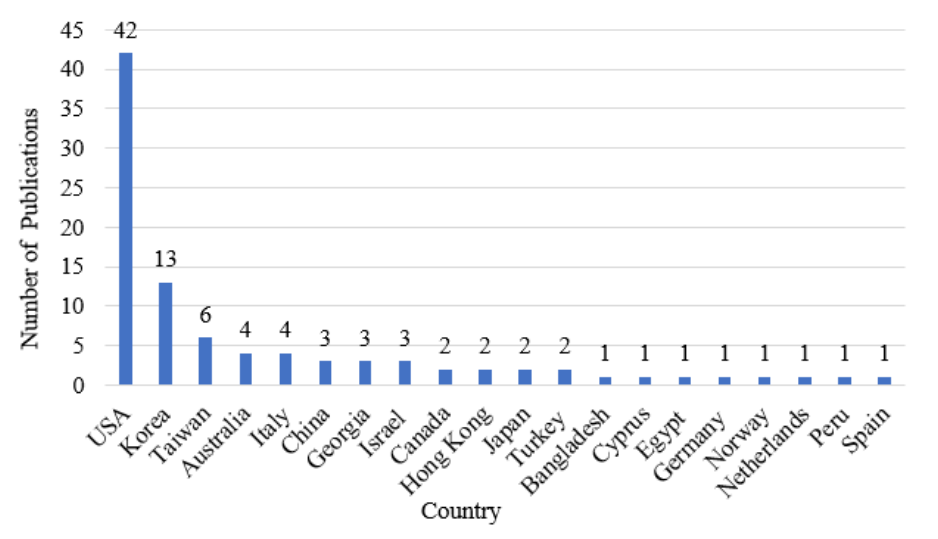

Fig. 3. Countries and publications

The low distribution can be interpreted as an immaturity of this research field, at least regarding global reach [52]; moreover, it could be due to the concentration of this study on publications written in English. As can be noted, USA comes first in terms of the number of publications comparing with the rest of the presented countries. This reflects the interest of academics and researchers in USA with AR and VR implementations, where it is expected that $\mathrm{AR}$ and VR will promote gross domestic product (GDP) in the U.S. by 49 billion U.S. dollars in 2021. South Korea came next with 13 publications (14\%), followed by Taiwan with six publications $(6 \%)$, and both Australia and Italy with four publications (4\%) and the rest of the publications came from several countries with a number of publications ranging from 3 to 1 .

\subsection{Technology features}

According to the used technology, the identified studies are classified to 42 studies related to AR technology, 46 studies related to VR technology, and 6 studies related to AR and VR. This section answers the research question regarding $A R$ and VR systems' features implemented in the CPM domain. The main features of each technology system were extracted and classified, where the identified features of AR technology are spatial registration method, display method, user interaction device, while for VR technology are display method, user interaction device, and level of immersion.
Display technology is an essential part of any AR or VR system. Since the visual system is the prevalent means of communication for most people, the visual display part of a VR or AR display has the most influence on the system's overall design [14]. Several types of display technology exist today, including head-mounted displays (HMDs), desktop displays, hand-held displays, and stationary displays. Table 3 illustrates the identified display methods for both AR and VR technologies and the number of applications within this review.

Among all display methods of AR technology, hand-held displays, which mainly refer to tablets and smartphones was the most widely used ones. This result may reflect the growing interest in improving and using mobile AR applications [2]. Furthermore, this growing interest may be due to several factors, including the improving performance of this display method, recent solutions to technical issues such as tracking, small production costs, and ease of use [2,54].

Table 3. AR and VR identified display methods

\begin{tabular}{lcc}
\hline \multirow{2}{*}{ Display method } & \multicolumn{2}{c}{ Number of applications } \\
\cline { 2 - 3 } & AR & VR \\
\hline HMD & 16 & 18 \\
Hand-held display & 18 & 4 \\
Desktop display & 8 & 13 \\
Projection-based display & 1 & 8 \\
Not mentioned & 4 & 6 \\
\hline
\end{tabular}


HMDs were the most widely used display method in VR technology. This result aligns with the literature [9], where the HMDs are the most commonly known method of VR display. Desktop display and projection-based display were identified in 13 and 8 studies, respectively. The high use of these displays may be explained by its providing of a relatively large portion of the field of view (FOV) for one or more users, the reduced amount of hardware worn by users, which result in improving the safety of the system, and its ease of accessibility [14,55]. Hand-held displays came with the least number of use (4) as a VR display method which also aligns with the literature that hand-held displays had not been widely used as a component of VR systems.

Real-time interaction with a composite environment in the case of AR or with a virtual environment in the case of VR is one of the main features of AR and VR technologies [15]. The used interaction devices in AR and VR systems were identified and illustrated in Table 4. The touch screen is the most used interaction device among all interaction methods of AR systems. This aligns with the high use of hand-held display devices, as mentioned previously. Next comes the traditional input method with keyboard and mouse, which were used mainly in conjunction with the desktop display; in addition to that, in some cases, HMDs used keyboard and mouse as interaction devices. Regarding VR systems, the controller, keyboard and mouse were identified as the most used interaction devices.

Table 4. Interaction devices

\begin{tabular}{lcc}
\hline \multirow{2}{*}{ Interaction device } & \multicolumn{2}{c}{ Number of applications } \\
\cline { 2 - 3 } & $\mathrm{AR}$ & $\mathrm{VR}$ \\
\hline Keyboard and mouse & 9 & 10 \\
Touch screen & 18 & 3 \\
Joystick & 2 & 4 \\
Controller & 2 & 11 \\
Smart glove & 1 & 0 \\
Not mentioned & 11 & 19 \\
\hline
\end{tabular}

The level of immersion is considered one of the key elements of any VR system that distinguishes this technology from conventional computergenerated technologies. Based on the level of immersion, the identified VR systems were classified into three categories: least-immersive, semi-immersive, and full-immersive [10]. Based on the results, the full-immersive VR system ranked first with the highest rate of use at $35 \%$, which returns to the popularity of HMDs as the most widely used display method for VR systems. Despite the expensive cost of such a system, it is preferred because of its ability to provide the highest level of immersion. It gives the user the feeling of being part of the virtual environment [10]. The least-immersive systems, also called Desktop VR systems, were used at 33\%. This high use of such a system may be returned to its simplicity of display, ease of accessibility, less need for hardware components, and it is considered the least expensive VR system [10,14,55]. The semiimmersive system has the lowest rate of use at $15 \%$. These systems are characterized by providing a higher level of immersion than the least-immersive systems whilst maintaining the desktop VR's simplicity [11]. CAVE is an example of such a system mainly used regarding safety management and education [56,57].

Spatial registration is one of the most important technical aspects of an AR system and is considered a core part of AR functionality [3]. Spatial registration is responsible for the imposing process of the virtual objects into the real environment view by calculating the user's correct spatial position and orientation in accordance with the real-world coordinate systems $[3,9]$. The spatial registration methods of the identified AR systems were extracted and classified into two categories: "marker-based" and "marker-less" methods, as shown in Table 5. The marker-based "image recognition" method is considered the most widely used spatial registration method within the included studies. The high use of this method may be returned to the simplicity, efficiency, and convenience of image recognition for superimposing virtual objects to the real world, 
where the image recognition method relies on extracting features from images instead of using complicated algorithms for calculating the relationship of relative positions [9]. Among the AR marker-less registration methods, GPS came first, where it was identified in 9 studies. The notable use of GPS may be explained by its suitability for use in a large open area such as a construction site and the ease of its signal receiving by common mobile devices [9].

\subsection{AR and VR application areas in $C P M$}

This part provides the answer to the research question related to identifying the application areas of AR and VR technologies in the CPM domain. The application areas within the included studies were extracted and classified under themes that represent the CPM aspects. The following sections illustrate descriptive summaries that includes a set of main studies for each application area.

\subsubsection{AR}

Various application areas of AR technology in the CPM domain were identified (Table 6).

\subsubsection{Safety management}

The construction industry is one of the most dangerous industries where serious accidents and high death rates are still encountered, resulting in serious cost overruns and project delays $[58,59]$. As illustrated in Table 6 , the results demonstrate a strong focus on developing AR-based systems to enhance construction safety management practices. Safety management represents the highest rate (36\%) as an application area of AR technology among the identified application areas.

Many researchers investigated the efficiency of using AR technology as a safety planning tool especially regarding the hazard identification aspect, also as safety education and training tool, as a heavy equipment operator training tool, and as an inspection tool [29,60-63]. Kim et al. [64] proposed a construction hazard avoidance system using AR technology and image-based localization technique.
Table 5. AR spatial registration methods

\begin{tabular}{lc}
\hline Spatial registration method & Number of applications \\
\hline Marker-based & 20 \\
2D image recognition & 3 \\
3D object recognition & \\
Marker-less & 9 \\
GPS & 3 \\
IMU & 1 \\
RFID & 2 \\
VIO & 10 \\
Not mentioned & \\
\hline
\end{tabular}

Table 6. AR application areas in the CPM domain

\begin{tabular}{lcc}
\hline Application area & $\begin{array}{c}\text { Number of } \\
\text { publications }\end{array}$ & $\%$ \\
\hline $\begin{array}{l}\text { Safety management } \\
\begin{array}{l}\text { Communication and data } \\
\text { acquisition }\end{array}\end{array}$ & 17 & $36 \%$ \\
$\begin{array}{l}\text { Visualization } \\
\begin{array}{l}\text { Construction management } \\
\text { education }\end{array}\end{array}$ & 7 & $15 \%$ \\
$\begin{array}{l}\text { Scheduling and project } \\
\text { progress tracking } \\
\begin{array}{l}\text { Defect and quality } \\
\text { management }\end{array}\end{array}$ & 4 & $9 \%$ \\
\begin{tabular}{l} 
Facility management \\
\hline
\end{tabular} & 3 & $6 \%$ \\
\hline
\end{tabular}

The proposed system involves three modules: site monitoring module, safety assessment module, and visualization module. The system enables workers to avoid hazards by proactively providing hazard information. Chen et al. [65] integrated AR technology, BIM, and path planning to develop an assistive interface for a teleoperated crane to overcome many problems associated with crane operation and ensure the quality and safety of the erection tasks.

Safety education is one of the important aspects of safety management to provide a safe and healthy work environment in construction. Within this context, Le et al. [58] presented a framework for using mobile $\mathrm{AR}$ and $\mathrm{VR}$ for experiential construction safety education. The study results 
revealed that the proposed framework could enrich safety education in terms of hazard recognition skills and awareness of safety procedures.

\subsubsection{Communication and data acquisition}

Effective communication and information management are crucial issues to the successful delivery of construction projects $[6,66]$. Communication and data acquisition as an application area for AR technology was identified in 9 studies. Chu et al. [26] used AR technology and BIM to enhance the workers' productivity by improving the information retrieval process. The proposed system enabled the participants to complete their tasks about 50\% faster than using 2D paper-based documentation, decreased the participants' mental workload, and reduced learning curve times compared to paper manuals [26]. Bae et al. [66] proposed a system that integrates markerless AR technology and image-based localization techniques to conduct field reporting and access project information. The study results revealed that the proposed system indeed could enhance the onsite information retrieval process and prompt field reporting [66]. Various researchers have also investigated the implementation of AR technology as a communication and information retrieval tool [67-72].

\subsubsection{Visualization}

The identified AR-related studies as a visualization tool contribute by 7 studies. The identified aspects for $\mathrm{AR}$ as a visualization tool in the CPM domain were "Design Review" [73], "Design and Constructability Review" [73-75], and "Visualization of Simulated Construction Operations" [65,76]. Using AR as visualization for collaborative design review assists in completing tasks much faster than the paper-based method, provides a higher level of immersion than paper drawing, could better facilitate problem-solving and creativity, and increase the productivity of work in a given amount of time [73]. Alsafouri and Ayer [74] found out that mobile AR can enable most of the actions and outcomes reported by prior works that used VR-based mock-ups or physical mock-ups. Furthermore, it was suggested that using different mobile computing devices presents the same AR environment led to different behaviours among users. The development of AR technology brings high opportunities for interactive and collaborative construction equipment operation modelling [77]. Kim et al. [77] proposed an ARbased system for identifying the optimum equipment operation scenario within dynamic, changeable construction progress. The study results demonstrate that the system has a robust prospect for significant advances in the construction planning process [77]. Behzadan and Kamat [78] proposed a method that could automatically create operation-level construction animations in outdoor AR.

\subsubsection{Construction management education}

The traditional teaching techniques or even called passive teaching techniques, such as coursework in core subjects and in-class instruction, lack to effective preparation of students to handle the complexities of real projects, which results in limited opportunities for hands-on experience $[79,80]$. From this point came the need to use advanced visualization technologies as teaching techniques to enhance the educational experience of the CPM students [79]. AR technology has the potential to become an advantageous pedagogical tool in CPM education and benefit students by assisting them in comprehending complex construction processes [79]. Furthermore, the AR technology has the ability to enhance the traditional learning experience as it provides: an interactive learning environment that engages students in teamwork and brainstorming activities resulting in improving communication and problem-solving skills, supporting discovery-based learning where students take control of their learning process, and the ability to make mistakes that in real-site would lead to safety and health-related problems [80]. Behzadan et al. [80] proposed a collaborative AR system as a supportive learning tool for the existing education methods in order to help students to gain an in-depth understanding of equipment operation and related operational safety. The study developed 
the first generation MagicBook (GEN-1), an ARbased enhanced book that enables students to manipulate and observe imposed 3D virtual objects while reading the corresponding information. Bademosi et al. [79] assessed the effectiveness of using AR technology as a novel pedagogical technique to enhance CPM students' understanding of the Spatio-temporal constraints of several construction assemblies. The proposed pedagogical relies on the superimposing of virtual construction elements and objects using AR technology on realtime site videos to bring job site experiences to the classroom. The results indicated that CPM students anticipated in AR-based lectures were better able to identify the construction components when compared to those students who anticipated in traditional in-class lectures. Furthermore, the results revealed that incorporating $\mathrm{AR}$ as a supplement tool in the classroom is the best tactic to promote the educational experience of CPM students [79]. Wu et al. [81] explored the potential use of AR and VR as a construction education tool and workforce development through conducting a comparative analysis between student novices and professional experts in terms of design review and assessment. The results indicated no statistically significant differences between students and experts, despite students' apparent lack of experience. $\mathrm{Wu}$ et al. [81] proposed using AR and VR to bridge experience gaps in existing construction education and training, thereby accelerating the development of experience among students and refine a skilled workforce.

\subsubsection{Scheduling and project progress tracking}

As illustrated in Table 6, the contribution of the AR technology as a tool for scheduling and project progress tracking represents $9 \%$ among the identified studies. AR technology can enhance the scheduling and project progress tracking aspects remarkably; it provides an integrated visualization of as-built and as-planned forms. Golparvar-Fard et al. [82] developed a modelling system called $\mathrm{D}^{4} \mathrm{AR}$ that registries spatial as-planned and as-built models to measure, analyze, and communicate the construction progress. A set of experiments were conducted to validate the proposed system, and it has been proven not only can it be used as a scheduling management and progress tracking tool, but it can also be used as a robust on-site tool for defect and quality control, site layout management, and off-site safety management and education. Kim et al. [83] proposed an AR-based 4D CAD system that provides $4 \mathrm{D}$ and $5 \mathrm{D}$ simulation objects based on real-time construction information. Instead of analyzing the schedule progress based on the fieldwork reports and digital photos, the proposed system enables the construction participants to examine the progress remotely. Zaher et al. [84] proposed a system that integrates AR with BIM, generates $4 \mathrm{D}$ and 5D models to track construction progress and cost and time control. The proposed system was developed using various tools such as Primavera P6 to develop time schedules, Autodesk Revit to develop BIM models, Autodesk Naviswork to develop the 5D models, and Metaio creator to create and deploy AR scenarios. The effectiveness of the proposed system was evaluated through semi-structured interviews, and the results demonstrated that the system might reduce the time of construction and explaining information, decrease errors comparing with using paperwork, increase the effectiveness of decision-making. AR as a scheduling and construction progress tracking tool is going to be one of the most used technologies in advanced CPM [6].

\subsubsection{Defect and quality management}

Quality and defect management is an initial aspect of CPM where the repeated and inevitable defects are considered one of the important causes of project cost and schedule overruns in the construction process. AR can play a significant role to bring automation in quality and defect management aspects. AR technology could be used as a useful tool for field inspection. The use of such technology leads to the proactive prevention of dimension deviation and commission error of many defects in a construction site [25]. Park et al. [25] proposed a system framework that integrates AR, $\mathrm{BIM}$, and ontology-based data, for proactive defect management. It is expected that the proposed 
system would improve the existing manual inspection practices. Kwon et al. [24] addressed using marker-based AR, BIM, and image matching techniques to evolve two defect management systems; a mobile AR-based defect management application that automatically detects dimension errors and omissions on construction sites, and an image-matching system that enables managers to inspect quality remotely. The AR-based defect management system provides proactive prevention of defects by enabling workers to augment component position information in advance of installation work. Furthermore, the system would highly progress the existing manual-based defect management process by enabling inspectors and site managers to check errors more efficiently and remotely [24].

\subsubsection{Facility management}

Within the scope of facility management, managers often need to connect physical objects to databaselike text-based information [85]. Access to the location or equipment-related information is supposed as the basis of the facility management system [86]. AR technology is, therefore, an excellent candidate to assist facility managers with their routine tasks where it provides an integrated interface for a live view of a space supplemented by database information [85]. Irizarry et al. [85] presented the first mobile AR as a data-access tool for facility management called InfoSPOT (Information Surveyed Point for Observation and Tracking). Williams et al. [87] proposed a costeffective and efficient tool called BIM2MAR that aims to assist managers in accessing information related to their tasks within the scope of facility management. The proposed tool relies on a process of bringing BIM data to a mobile AR environment. Baek et al. [86] integrated AR technology and image-based indoor localization to develop facility management systems. The system assesses a user's orientation and position by comparing the user's perspective to BIM data based on a deep learning computation. The proposed system was evaluated through an expert interview and a real case study. The case study scenario represented a general facility management situation when a current location and related information of sanitary pipe was needed for a facility manager. The results revealed an agreement that $\mathrm{AR}$ is a powerful and effective tool for displaying facility management information and expected that the proposed system would effectively ease communication among onsite workers than using verbal explanation [86].

\subsubsection{VR}

Various application areas of VR technology in the CPM domain were identified (Table 7).

\subsubsection{Construction safety management}

VR technology has attracted great attention as a valuable construction safety management tool. As indicated in Table 7, about $50 \%$ of the included VRbased studies concerned safety management aspects. The typical aspects of VR-based construction safety management can be generally classified as safety planning and safety training and education. Li et al. [88] used VR to develop an interactive construction safety assessment system called Virtual Safety Assessment System (VSAS). The safety assessment system could assess workers' awareness in identifying unsafe working environments, unsafe working attitudes, and unsafe working methods. Getuli et al. [59] integrated IVR with BIM to facilitate the sharing of safety-related information, enhancing construction workspace planning.

Table 7. VR application areas in the CPM domain

\begin{tabular}{lcc}
\hline Application area & $\begin{array}{c}\text { Number of } \\
\text { publications }\end{array}$ & $\%$ \\
\hline $\begin{array}{l}\text { Construction safety } \\
\text { management }\end{array}$ & 26 & $51 \%$ \\
$\begin{array}{l}\text { Visualization } \\
\begin{array}{l}\text { Communication and data } \\
\text { acquisition }\end{array}\end{array}$ & 6 & $17 \%$ \\
$\begin{array}{l}\text { Construction management } \\
\text { education }\end{array}$ & 5 & $12 \%$ \\
$\begin{array}{l}\text { Scheduling and project } \\
\text { progress tracking }\end{array}$ & 5 & $10 \%$ \\
\hline
\end{tabular}


Construction safety education and training programs have proven to affect construction job sites' safety performance [41]. These programs are crucial for providing solid knowledge and cultivating skills for novices or students before entering the construction industry, which aids reduce injuries and fatal accidents rates on construction sites [89]. Safety knowledge is usually gained through traditional education or training methods, which in many cases were found inadequate to engage and motivate learners or trade workers to learn about safety and health matters and unable to provide realistic and practical experiences $[41,58]$. VR technology affords new opportunities for effective construction safety education and training of students and workers, providing higher risk cognition and fewer hazard exposure [10]. In order to improve the construction safety experiential learning, Le et al. [90] proposed a social VR-based system that enables learners to implement role-playing, dialogic learning, and social interaction for construction safety education. Pham et al. [89] used panoramic VR to develop a construction safety education system called Virtual Field Trip System (VIFITS). VIFITS is considered a powerful pedagogical tool that brings construction field trips to classrooms, provides practical safety experience, and improves students' safety knowledge compared with traditional education methods [89]. Li et al. [43] developed a Multiuser Virtual Safety Training System (MVSTS) that provides close-to-reality training for workers involved in tower crane dismantlement. Sacks et al. [91] investigated the efficiency of using immersive VR for workers training and found out that immersive VR provides more effective safety training and maintains a higher level of trainees' awareness and concentration than conventional training methods. Several VR-based systems have been developed to enhance hazard identification and recognition [92-95].

\subsubsection{Visualization}

VR technology as a visualization tool was found at $17 \%$ with nine studies. Recent researches proposed VR technology as a highly valued tool for collaborative decision-making in the design review process $[35,96,97]$. Paes and Irizarry [98] evaluated the usability of immersive VR technology as a visualization tool for design review from the users' standpoint. The results revealed the efficiency of VR in communicating design ideas and enhancing the communication in design review meetings among stakeholders. Calderon-Hernandez et al. [99] found that VR technology as a visualization tool could perform more effectively in terms of user's perception accuracy and memory and comprehension of objects compared with 2D paperbased drawings. Berg et al. [100] provided in-depth insights into how clients and designers could use VR to support the design review process with premeetings using VR environments. The walkthrough VR model enabled clients to visualize a project in advance and detect problematic design issues; moreover, the clients who used VR were empowered to contribute to the discussion related to identified design issues and participating feedback on a design proposal [100]. Liu et al. [101] evaluated the impact of VR on design review meetings and provided to project teams valuable insights into the pros and cons of adopting VR to support design review meetings. To overcome one of the most technical problems with the existing $\mathrm{VR}$, which is the difficulty and time consuming of converting design data into VR displays, Du et al. [102] proposed a BIM-VR based system called BVRS that enables real-time automation of the updates of design information in VR displays automatically and simultaneously.

\subsubsection{Communication and data acquisition}

Recently the construction industry has paid great attention to VR technology as a project communication tool [37]. Du et al. [37] proposed a VR-based system called Collaborative Virtual Reality (CoVR) as an interactive project communication tool. The proposed system enhances communication in construction tasks and reduces the number of change orders and requests for information. Using VR technology and on-site cameras, Liu et al. [103] developed a novel method for retrieving spatial information. Based on 
geometric information such as dimensions and position data of construction objects retrieved from on-site videos, the developed model allows to create and update real-time virtual construction scene reflecting site conditions which enable engineers to distinguish safe areas and hazard areas, to re-plan construction operations on a virtual environment instead of risking them in a real construction site [103]. Abbas et al. [104] assessed the effectiveness of using immersive VR technology as a project communication tool through a comparative analysis between immersive VR-based communication and traditional face-toface discussion and found out that both methods provided effective communication regarding communication richness, communication openness, and discussion quality.

\subsubsection{Construction management education}

The value of VR technology as a pedagogical tool returns to providing students with the opportunity to explore and visualize $3 \mathrm{D}$ construction information in real-time and dynamic environments [105]. Le et al. [106] proposed a VR-based system to provide an experiential learning experience to prevent defects and enhance construction quality knowledge. The results revealed that the proposed system compared with the traditional lectures is more interactive and engaging, proving its simplicity and ease to follow. Furthermore, the results showed the system's capability to improve the learners' defect identification abilities and risk cognition. Three generations of virtual construction simulators (VCS) were developed for teaching construction management concepts VCS 1 [107], VCS 2 [105], VCS 3 [108]. The developed simulators enabled learners to create, visualize, and review construction schedules. The results showed the ability of the simulators to enhance the learners' knowledge of time, cost, resource management, as well as factors that affect construction progress [108].

\subsubsection{Scheduling and project progress tracking}

Kim and Kano [109] proposed a new method of construction progress control by comparing photo images of a real construction site, which reflects the exact site situation, with the planned VR images simulated in a virtual environment. The comparing process of both real and virtual images enables observing the differences between as-planned and as-built models. It enables retrieving of useful information with feedback on the planning of the construction process [109]. Change orders are one of the most common reasons for construction delays. Balali et al. [110] integrated the immersive VR technology with BIM and cost database to develop a cost estimating approach that enables engineers and stakeholders to visualize and interact with models in realistic virtual environments and comprehend the dollar amount changes resulting from change orders. The results revealed that the proposed system could be considered a cost estimation tool that allows conducting change orders virtually and assessing alternative designs and construction methods to present the cost impacts with each change [110]. Bademosi et al. [111] also proposed a framework for integrating technology and BIM to streamline the construction cost estimation process.

\section{Conclusion}

In recent years, many researchers have focused on the implementation of AR and VR technologies concerning CPM aspects, where these technologies have shown promising futures to advance the CPM domain and have shown a significant contribution to the advancement of this sector in many areas such as cost and time management, defect management, safety management, education and training, progress monitoring and tracking, and onsite information access. This study provides a breadth of coverage of the available literature about AR and VR technologies in CPM, which provides a better understanding of the nature, size, and scope of research activity in this field. Furthermore, this study aimed to identify the main application areas of AR and VR technologies in the CPM and the characteristics of these technologies, which in turn provides a comprehensive platform for the researchers and practitioners to explore the potential application areas, understand the effective 
use of these technologies, and propose new use cases.

It is clear from the recent studies that there is a massive contribution to developing $\mathrm{AR}$ and VR systems for use in the construction safety management aspects. Many studies have proven the efficiency of these technologies for use in many aspects regarding safety planning, safety training and education, and construction equipment operator training. AR and VR implementations regarding project scheduling and construction progress tracking has a great potential to enhance the traditional methods, and it is proposed to have a promising role in the advanced CPM domain. AR and VR are proven tools for improving communication and data acquisition. AR technology has proved its ability to enhance on-site information retrieval, improving the effectiveness and efficiency of workers' tasks, and prompting field reporting, while VR technology proposed as a valuable tool for a multidisciplinary communication tool in early phase of projects. AR is greatly appreciated by researchers for its efficiency in defect and quality management aspects, as it is distinguished from traditional methods by playing an important role by providing proactive prevention of many defects in a construction site and enabling inspectors and site managers to check errors more efficiently and remotely. Both AR and VR technologies are highly proposed as a pedagogical tool for teaching CPM aspects and concepts, where both technologies have proven their efficiency compared to the traditional learning methods in teaching CPM concepts. The advantages of both VR and AR played an important role in using it for the purpose of visualization. Both technologies are proven tools for supporting design and constructability review meetings by enhancing decision making in the design review process and enhancing the communication among stakeholders.

\section{Declaration of conflicting interests}

The author(s) declared no potential conflicts of interest with respect to the research, authorship, and/or publication of this article.

\section{References}

[1] Shin DH, Dunston PS (2008) Identification of application areas for Augmented Reality in industrial construction based on technology suitability. Automation in Construction 17(7): 882894.

[2] Rankohi S, Waugh L (2013) Review and analysis of augmented reality literature for construction industry. Visualization in Engineering 1(1): 1-9.

[3] Chi HL, Kang SC, Wang X (2013) Research trends and opportunities of augmented reality applications in architecture, engineering, and construction. Automation in Construction 33: 116-122.

[4] Liu F, Seipel S (2018) Precision study on augmented reality-based visual guidance for facility management tasks. Automation in Construction 90: 79-90.

[5] Wang X, Kim MJ, Love PED, Kang SC (2013) Augmented reality in built environment: Classification and implications for future research. Automation in construction 32: 1-13.

[6] Ahmed S (2018) A review on using opportunities of augmented reality and virtual reality in construction project management. Organization, Technology and Management in Construction 10(1): 1839-1852.

[7] Delgado JMD, Oyedele L, Beach T, Demian P (2020) Augmented and virtual reality in construction: drivers and limitations for industry adoption. Journal of Construction Engineering and Management 146(7): 04020079.

[8] Noghabaei M, Heydarian A, Balali V, Han K (2020) Trend analysis on adoption of virtual and augmented reality in the architecture, engineering, and construction industry. Data 5(1): 26.

[9] Cheng J, Chen K, Chen W (2020) State-of-the-art review on mixed reality applications in the AECO industry. Journal of Construction Engineering and Management 146(2): 03119009.

[10] Li X, Yi W, Chi HL, Wang XY, Chan APC (2018) A critical review of virtual and augmented reality (VR/AR) applications in construction safety. Automation in Construction 86: 150-62.

[11] Wang P, Wu P, Wang J, Chi H-L, Wang X (2018) A critical review of the use of virtual reality in construction engineering education and training. International Journal of Environmental Research and Public Health 15(6): 1204.

[12] Schmalstieg D, Hollerer T. Augmented Reality: Principles and Practice. Addison-Wesley Professional, 2016. 
[13] Furht B. Handbook of Augmented Reality. Springer, New York, NY, 2011.

[14] Craig AB, Sherman WR, Will JD. Developing Virtual Reality Applications: Foundations of Effective Design. Morgan Kaufmann, 2009.

[15] Mihelj M, Novak D, Beguš S. Virtual Reality Technology and Applications. Springer, 2014.

[16] Fuchs P, Moreau G, Guitton P. Virtual Reality: Concepts and Technologies. CRC Press, 2011.

[17] Piroozfar P, Essa A, Farr ERP. The application of Augmented Reality and Virtual Reality in the construction industry using wearable devices. 9th International Conference on Construction in the 21st Century (CITC-9) 2017, Dubai, United Arab Emirates.

[18] Peddie J. Augmented Reality: Where We Will All Live. Springer, 2017.

[19] Wang X (2009) Augmented reality in architecture and design: potentials and challenges for application. International Journal of Architectural Computing 7(2): 309-326.

[20] Zhou Y, Luo H, Yang Y (2017) Implementation of augmented reality for segment displacement inspection during tunneling construction. Automation in Construction 82: 112-121.

[21] Shin D, Dunston PS (2009) Evaluation of augmented reality in steel column inspection. Automation in Construction 18(2): 118-129.

[22] Behzadi A (2016) Using augmented and virtual reality technology in the construction industry. American Journal of Engineering Research 5(12): 350-353.

[23] Golparvar-Fard M, Peña-Mora F, Savarese S (2009) D4AR-a 4-dimensional augmented reality model for automating construction progress monitoring data collection, processing and communication. Journal of Information Technology in Construction (ITcon) 14(13): 129153.

[24] Kwon OS, Park CS, Lim CR (2014) A defect management system for reinforced concrete work utilizing BIM, image-matching and augmented reality. Automation in Construction 46: 74-81.

[25] Park CS, Lee DY, Kwon OS, Wang X (2013) A framework for proactive construction defect management using BIM, augmented reality and ontology-based data collection template. Automation in Construction 33: 61-71.

[26] Chu M, Matthews J, Love PED (2018) Integrating mobile building information modelling and augmented reality systems: an experimental study. Automation in Construction 85: 305-316.

[27] Dong S, Behzadan AH, Chen F, Kamat VR (2013) Collaborative visualization of engineering processes using tabletop augmented reality. Adv Eng Softw 55: 45-55.

[28] Pereira RE, Gheisari M, Esmaeili B. Using panoramic augmented reality to develop a virtual safety training environment. Construction Research Congress 2018, April 2-4 2018, New Orleans, Louisiana.

[29] Han S, Peña-Mora F, Golparvar-Fard M, Roh S. Application of a visualization technique for safety management. International Workshop on Computing in Civil Engineering 2009, 543-551.

[30] Wang X, Schnabel MA. Mixed Reality in Architecture, Design, and Construction. Springer, 2008.

[31] Oesterreich T, Teuteberg F. Evaluating augmented reality applications in construction-a cost-benefit assessment framework based on VoFI. 25th European Conference on Information Systems (ECIS), 2017, Guimarães, Portugal.

[32] Bademosi F, Issa RRA. Business value of augmented reality in the construction industry. Construction Research Congress 2018, New Orleans, Louisiana, USA.

[33] Ahmed S, Hossain MM, Hoque MI (2017) A brief discussion on augmented reality and virtual reality in construction industry. Journal of System Management Sciences 7(3): 1-33.

[34] Bouchlaghem D, Shang H, Whyte J, Ganah A (2005) Visualisation in architecture, engineering and construction (AEC). Automation in Construction 14(3): 287-295.

[35] Boton C (2018) Supporting constructability analysis meetings with Immersive Virtual Realitybased collaborative BIM 4D simulation. Automation in Construction 96: 1-15.

[36] Wolfartsberger J (2019) Analyzing the potential of virtual reality for engineering design review. Automation in Construction 104: 27-37.

[37] Du J, Shi Y, Zou Z, Zhao D (2018) CoVR: Cloudbased multiuser virtual reality headset system for project communication of remote users. Journal of Construction Engineering and Management 144(2): 04017109.

[38] Albert A, Hallowell MR, Kleiner B, Chen A, Golparvar-Fard M (2014) Enhancing construction hazard recognition with high-fidelity Augmented 
Virtuality. Journal of Construction Engineering and Management 140(7): 04014024.

[39] Moore HF, Eiris R, Gheisari M, Esmaeili B. Hazard identification training using 360-degree panorama vs. virtual reality techniques: a pilot study. Computing in Civil Engineering 2019: Visualization, Information Modeling, and Simulation, June 17-19 2019, Atlanta, Georgia, USA.

[40] Fang Y, Teizer J. A multi-user virtual 3D training environment to advance collaboration among crane operator and ground personnel in blind lifts. Computing in Civil and Building Engineering (2014), June 23-25 2014, Orlando, Florida, United States.

[41] Pedro A, Le QT, Park CS (2016) Framework for integrating safety into construction methods education through interactive virtual reality. Journal of Professional Issues in Engineering Education and Practice 142(2): 04015011.

[42] Kamath RS, Dongale TD, Kamat RK (2012) Development of virtual reality tool for creative learning in architectural education. International Journal of Quality Assurance in Engineering Technology Education 2(4): 16-24.

[43] Li H, Chan G, Skitmore M (2012) Multiuser virtual safety training system for tower crane dismantlement. Journal of Computing in Civil Engineering 26(5): 638-647.

[44] Kiral IA, Comu S. Safety training for scaffolding and formwork construction by using virtual environment. 34th International Conference of CIB W78, 2017, Heraklion, Crete, Greece.

[45] Kim M, Wang X, Love P, Li H, Kang SC (2013) Virtual reality for the built environment: a critical review of recent advances. Journal of Information Technology in Construction 18: 279-305.

[46] Ozcan-Deniz G (2019) Expanding applications of virtual reality in construction industry: A multiple case study approach. Journal of Construction Engineering, Management \& Innovation 2(2): 4866.

[47] Levac D, Colquhoun H, O'Brien KK (2010) Scoping studies: advancing the methodology. Implementation science 5(1): 69.

[48] Daudt HML, van Mossel C, Scott SJ (2013) Enhancing the scoping study methodology: a large, inter-professional team's experience with Arksey and O'Malley's framework. BMC Medical Research Methodology 13(1): 48.
[49] Arksey H, O'Malley L (2005) Scoping studies: towards a methodological framework. International Journal of Social Research Methodology 8(1): 1932.

[50] Tricco AC, Lillie E, Zarin W, O'Brien K, Colquhoun H, Kastner M, Levac D, Ng C, Sharpe JP, Wilson K, Kenny M, Warren R, Wilson C, Stelfox HT, Straus SE (2016) A scoping review on the conduct and reporting of scoping reviews. BMC medical research methodology 16(1): 15 .

[51] Peters M, Godfrey C, McInerney P, Soares CB, Khalil H, Parker D. Methodology for JBI scoping reviews. The Joanna Briggs Institute Reviewers manual 2015, The Joanna Briggs Institute, 2015, 3-24.

[52] Engebø A, Lædre O, Young B, Larssen PF, Lohne J, Klakegg OJ (2020) Collaborative project delivery methods: a scoping review. Journal of Civil Engineering and Management 26(3): 278303.

[53] Colquhoun HL, Levac D, O'Brien KK, Straus S, Tricco AC, Perrier L, Kastner M, Moher D (2014) Scoping reviews: time for clarity in definition, methods, and reporting. Journal of Clinical Epidemiology 67(12): 1291-1294.

[54] Van Krevelen DWF, Poelman R (2010) A survey of augmented reality technologies, applications and limitations. International journal of virtual reality 9(2): 1-20.

[55] Wen J, Gheisari M (2020) Using virtual reality to facilitate communication in the AEC domain: a systematic review. Construction Innovation 20(3): 509-542.

[56] Perlman A, Sacks R, Barak R (2014) Hazard recognition and risk perception in construction. Safety Science 64: 22-31.

[57] Leder J, Horlitz T, Puschmann P, Wittstock V, Schutz A (2019) Comparing immersive virtual reality and powerpoint as methods for delivering safety training: Impacts on risk perception, learning, and decision making. Safety Science 111: 271-286.

[58] Le QT, Pedro A, Lim CR, Park HT, Park CS, Kim HK (2015) A framework for using mobile based virtual reality and augmented reality for experiential construction safety education. International Journal of Engineering Education 31(3): 713-725.

[59] Getuli V, Capone P, Bruttini A, Isaac S (2020) BIM-based immersive virtual reality for construction workspace planning: A safety- 
oriented approach. Automation in Construction 114: 103160.

[60] Eiris R, Gheisari M, Esmaeili B (2018) PARS: Using augmented 360-degree panoramas of reality for construction safety training. International journal of environmental research public health 15(11): 2452.

[61] Park CS, Kim HJ (2013) A framework for construction safety management and visualization system. Automation in Construction 33: 95-103.

[62] Pereira RE, Moore H, Gheisari M, Esmaeili B. Development and usability testing of a panoramic augmented reality environment for fall hazard safety training. Advances in Informatics and Computing in Civil and Construction Engineering, Springer, 2019, 271-279.

[63] Eiris R, Jain A, Gheisari M, Wehle A (2020) Safety immersive storytelling using narrated 360-degree panoramas: A fall hazard training within the electrical trade context. Safety Science 127: 104703

[64] Kim K, Kim H, Kim H (2017) Image-based construction hazard avoidance system using augmented reality in wearable device. Automation in Construction 83: 390-403.

[65] Chen YC, Chi HL, Kang SC, Hsieh SH (2016) Attention-based user interface design for a teleoperated crane. Journal of Computing in Civil Engineering 30(3): 04015030.

[66] Bae H, Golparvar-Fard M, White J (2015) Imagebased localization and content authoring in structure-from-motion point cloud models for realtime field reporting applications. Journal of Computing in Civil Engineering 29(4): B4014008.

[67] Kim C, Park T, Lim H, Kim H (2013) On-site construction management using mobile computing technology. Automation in Construction 35: 415423.

[68] Bae H, Golparvar-Fard M, White J (2013) Highprecision and infrastructure-independent mobile augmented reality system for context-aware construction and facility management applications. ASCE International Workshop on Computing in Civil Engineering 637-44.

[69] Tsai MK, Yau NJ (2014) Using mobile disaster response system in bridge management. Journal of Civil Engineering and Management 20(5): 737745.

[70] Ratajczak J, Riedl M, Matt DT (2019) BIM-based and $\mathrm{AR}$ application combined with location-based management system for the improvement of the construction performance. Buildings 9(5): 118.

[71] Lin TH, Liu CH, Tsai MH, Kang SC (2015) Using augmented reality in a multiscreen environment for construction discussion. Journal of Computing in Civil Engineering 29(6): 04014088.

[72] Yeh KC, Tsai MH, Kang SC (2012) On-site building information retrieval by using projectionbased Augmented Reality. Journal of Computing in Civil Engineering 26(3): 342-355.

[73] Wang X, Dunston PS (2013) Tangible mixed reality for remote design review: a study understanding user perception and acceptance. Visualization in Engineering 1(1): 8.

[74] Alsafouri S, Ayer SK (2019) Mobile augmented reality to influence design and constructability review sessions. J Archit Eng 25(3): 11.

[75] Alsafouri S, Ayer SK (2019) Leveraging mobile augmented reality devices for enabling specific human behaviors in design and constructability review. Adv Civ Eng 2019: 11.

[76] Hammad A, Wang H, Mudur SP (2009) Distributed augmented reality for visualizing collaborative construction tasks. Journal of Computing in Civil Engineering 23(6): 418-427.

[77] Kim B, Kim C, Kim H (2012) Interactive modeler for construction equipment operation using Augmented Reality. Journal of Computing in Civil Engineering 26(3): 331-341.

[78] Behzadan AH, Kamat VR (2009) Automated generation of operations level construction animations in outdoor Augmented Reality. Journal of Computing in Civil Engineering 23(6): 405-417.

[79] Bademosi F, Blinn N, Issa RRA (2019) Use of augmented reality technology to enhance comprehension of construction assemblies. J Inf Technol Constr 24: 58-79.

[80] Behzadan AH, Iqbal A, Kamat VR. A collaborative augmented reality based modeling environment for construction engineering and management education. In: Jain S, Creasey R, Himmelspach J. (ed) Proceedings of the 2011 Winter Simulation Conference, IEEE, 2011, 3568-3576.

[81] Wu W, Hartless J, Tesei A, Gunji V, Ayer S, London J (2019) Design assessment in virtual and mixed reality environments: comparison of novices and experts. Journal of Construction Engineering and Management 145(9): 04019049.

[82] Golparvar-Fard M, Pena-Mora F, Savarese S (2011) Integrated sequential as-built and asplanned representation with $\mathrm{D}(4) \mathrm{AR}$ tools in 
support of decision-making tasks in the AEC/FM industry. Journal of Construction Engineering and Management 137(12): 1099-116.

[83] Kim HS, Kim SK, Borrmann A, Kang LS (2018) Improvement of realism of 4D objects using Augmented Reality objects and actual images of a construction site. KSCE Journal of Civil Engineering 22(8): 2735-2746.

[84] Zaher M, Greenwood D, Marzouk M (2018) Mobile augmented reality applications for construction projects. Construction Innovation 18(2): 152-166.

[85] Irizarry J, Gheisari M, Williams G, Walker BN (2013) InfoSPOT: A mobile Augmented Reality method for accessing building information through a situation awareness approach. Automation in Construction 33: 11-23.

[86] Baek F, Ha I, Kim H (2019) Augmented reality system for facility management using image-based indoor localization. Automation in Construction 99: 18-26.

[87] Williams G, Gheisari M, Chen P-J, Irizarry J (2015) BIM2MAR: An efficient BIM translation to mobile augmented reality applications. J Manage Eng 31(1): A4014009.

[88] Li H, Chan G, Skitmore M (2012) Visualizing safety assessment by integrating the use of game technology. Automation in Construction 22: 498505.

[89] Pham HC, Dao NN, Pedro A, Le QT, Hussain R, Cho S, Park CS (2018) Virtual field trip for mobile construction safety education using 360-degree panoramic Virtual Reality. International Journal of Engineering Education 34(4): 1174-1191.

[90] Le QT, Pedro A, Park CS (2015) A social virtual reality based construction safety education system for experiential learning. Journal of Intelligent \& Robotic Systems 79(3): 487-506.

[91] Sacks R, Perlman A, Barak R (2013) Construction safety training using immersive virtual reality. Construction Management Economics 31(9): 10051017.

[92] Fang Y, Teizer J, Marks E. A framework for developing an as-built virtual environment to advance training of crane operators. Construction Research Congress 2014, May 19-21 2014, Atlanta, Georgia.

[93] Jeelani I, Han K, Albert A. Development of Immersive Personalized Training Environment for Construction Workers. Computing in Civil
Engineering 2017, June 25-27 2017, Seattle, Washington, USA.

[94] Jeelani I, Han K, Albert A (2020) Development of virtual reality and stereo-panoramic environments for construction safety training. Engineering, Construction Architectural Management 27(8): 1853-1876.

[95] Lu XQ, Davis S (2018) Priming effects on safety decisions in a virtual construction simulator. Eng Constr Archit Manag 25(2): 273-294.

[96] Liu Y, Lather J, Messner J. Virtual reality to support the integrated design process: A retrofit case study. 2014 International Conference on Computing in Civil and Building Engineering, June 23-25 2014, Orlando, Florida, United States.

[97] Zaker R, Coloma E (2018) Virtual realityintegrated workflow in BIM-enabled projects collaboration and design review: a case study. Visualization in Engineering 6(1): 4.

[98] Paes D, Irizarry J. A usability study of an immersive Virtual Reality platform for building design review: Considerations on human factors and user interface. Construction Research Congress 2018, April 2-4 2018, New Orleans, Louisiana.

[99] Calderon-Hernandez C, Paes D, Irizarry J, Brioso $\mathrm{X}$. Comparing Virtual Reality and 2-dimensional drawings for the visualization of a construction project. ASCE International Conference on Computing in Civil Engineering 2019, June 17-19 2019 Atlanta, Georgia.

[100] Berg M, Hartmann T, Graaf R (2017) Supporting design reviews with pre-meeting virtual reality environments. J Inf Technol Constr 22(16): $305-$ 321.

[101] Liu Y, Castronovo F, Messner J, Leicht R (2020) Evaluating the impact of virtual reality on design review meetings. Journal of Computing in Civil Engineering 34(1): 04019045.

[102] Du J, Zou ZB, Shi YM, Zhao D (2018) Zero latency: Real-time synchronization of BIM data in virtual reality for collaborative decision-making. Automation in Construction 85: 51-64.

[103] Liu CW, Wu TH, Tsai MH, Kang SC (2018) Image-based semantic construction reconstruction. Automation in Construction 90: 67-78.

[104] Abbas A, Choi M, Seo J, Cha SH, Li H (2019) Effectiveness of immersive Virtual Reality-based communication for construction projects. KSCE Journal of Civil Engineering 23(12): 4972-4983. 
[105] Nikolic D, Jaruhar S, Messner JI (2011) Educational simulation in construction: virtual construction simulator1. Journal of Computing in Civil Engineering 25(6): 421-429.

[106] Le QT, Pedro A, Pham HC, Park CS (2016) A virtual world based construction defect game for interactive and experiential learning. Int J Eng Educ 32: 457-467.

[107] Lee S, Scholar P-D, Messner JI. The virtual construction simulator: Evaluating an educational simulation application for teaching construction management concepts. 27th International Conference of CIB W78, 2010, Cairo, Egypt.

[108] Lee S, Nikolic D, Messner JI (2015) Framework of the virtual construction simulator 3 for construction planning and management education. Journal of Computing in Civil Engineering 29(2): 05014008.

[109] Kim H, Kano N (2008) Comparison of construction photograph and VR image in construction progress. Automation in Construction 17(2): 137-143.

[110] Balali V, Zalavadia A, Heydarian A (2020) Realtime interaction and cost estimating within immersive virtual environments. Journal of Construction Engineering and Management 146(2): 04019098.

[111] Bademosi FM, Tayeh R, Issa RRA. An immersive approach to construction cost estimating. ASCE International Conference on Computing in Civil Engineering 2019, June 17-19 2019, Atlanta, Georgia. 


\section{Appendix}

A1. Relevance screening form on the basis of title, abstract, and keywords

\begin{tabular}{|c|c|c|c|}
\hline \multicolumn{2}{|c|}{ Question } & \multirow{2}{*}{$\begin{array}{ll}\text { Options } \\
\text { - } & \text { Journal article (go to question 2) } \\
\text { - } & \text { Conference proceedings paper } \\
& \text { (go to question 2) } \\
\text { - } & \text { Others (e.g. book chapter) }\end{array}$} & \multirow{2}{*}{$\begin{array}{l}\text { Exclusion if } \\
\text { Result of category "others" }\end{array}$} \\
\hline 1) & $\begin{array}{l}\text { What type of source is the } \\
\text { result? }\end{array}$ & & \\
\hline 2) & Is an abstract available? & $\begin{array}{l}\text { - } \quad \text { Yes (go to question 3) } \\
\text { - } \quad \text { No (go to question 2a) }\end{array}$ & \\
\hline \multicolumn{2}{|c|}{$\begin{array}{l}\text { 2a) Can it be concluded from the } \\
\text { title that the article deals with AR or } \\
\text { VR? }\end{array}$} & $\begin{array}{l}\text { - Yes (article will stay for further } \\
\text { review process) } \\
\text { - No }\end{array}$ & No \\
\hline 3) & $\begin{array}{l}\text { Does the article concern any of } \\
\text { the Construction Project } \\
\text { Management aspects? }\end{array}$ & $\begin{array}{l}\text { - Yes (article will remain for } \\
\text { further review process) } \\
\text { - No }\end{array}$ & No \\
\hline
\end{tabular}

A2. Eligibility screening form on basis of full-text screening

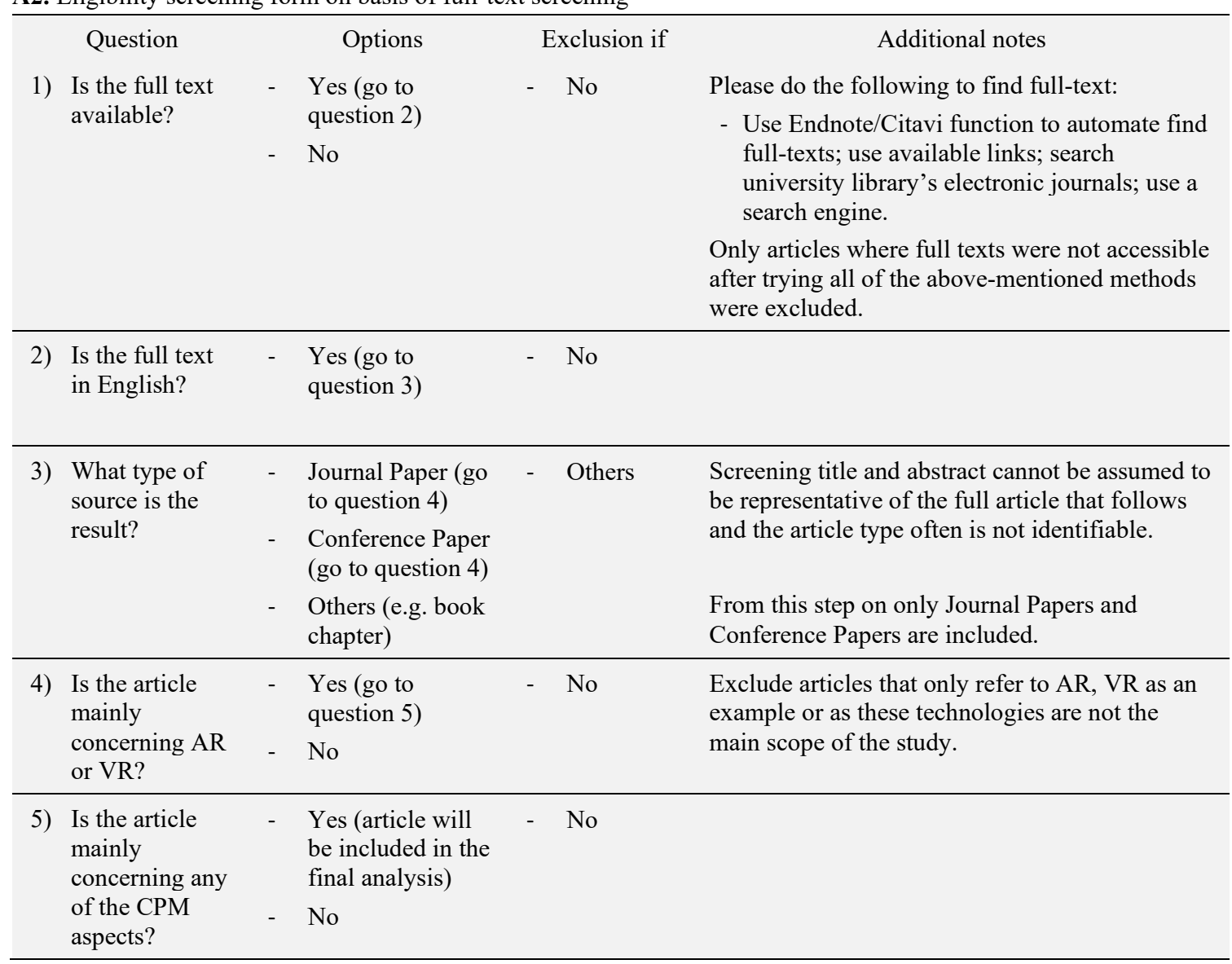

